\title{
Effect of Hot-pressing Process on Mechanical Properties and Color Changes of Poplar Powder Compacts
}

\author{
Zhizhong Long, Liqiang Zhang, * Zhili Tan, Qingding Wu, and Jin Yan
}

Binderless poplar powder compacts were prepared using the hot-pressing technology. The effect of the forming process on the mechanical properties and surface color of the poplar powder compacts was studied. The effect of forming temperature on mechanical properties and surface color was more noticeable than the forming pressure and the holding time. With the change of the forming process parameters, the static bending strength of the compacts increased first and then decreased. The overall change trend of the surface hardness increased continuously. The overall color difference $\left(\Delta E^{*}\right)$ of the compacts increased with the change of forming process parameters and the surface color deepened gradually. The results of Fourier transform infrared (FTIR) spectroscopy showed that hemicellulose, cellulose, and lignin in the compacts were greatly affected by the forming process parameters. The degradation of hemicellulose and cellulose produced many colored substances, and the content of lignin increased. These made the surface color of compacts deepen.

Keywords: Poplar powder; Hot-pressing; Mechanical properties; Surface color; FTIR; Binderless

Contact information: College of Mechanical and Electrical Engineering, Central South University of Forestry and Technology, Changsha 410004 China; *Corresponding author: $21384881 @$ qq.com

\section{INTRODUCTION}

With the improvement of people's requirements for the quality of life, wood products are currently being popularized, increasing the demand for wood. However, the utilization rate of resources during wood products processing and manufacturing is not high. Such practices will result in large amounts of forestry residues and cause resource waste and economic losses. The flow chart of the hot-press forming is shown in Fig. 1. Hot-pressing technology is a new technology based on the combination of non-adhesive hot-pressing of wood materials and hot-pressing of metal powder. The forestry residues after hot-pressing can be prepared as a new material with high density and high added value.

The earliest international research on so-called "binderless" wood products was in 1939. Researcher improved the bonding performance after chemical treatment of wood surface. This method was patented in the United States. Since then, many countries began to study the influence of chemical treatment on the bonding performance of wood surface. China also began to study binderless wood products in the 1960s.

In preparation of binderless wood products, the goal is that there be no harmful artificial additives such as glue, which otherwise could contribute to pollution during the forming process. Though no binder is used, the manufacturer still has to meet requirements for strength and dimensional stability. Meeting such goals will be depending on the intensity (temperature, pressure, time) or pressing, along with any chemical changes or 
flows of material that happen during pressing. It not only has environmental benefits but can effectively solve the problem of resource waste in the actual production process of wood products and subsequent treatment of forestry residues (Zhang et al. 2020).

In this paper, the changes in the static mechanical properties of hot-pressed compacts were evaluated. An international standard colorimetric system using the CIE method was applied to measure the change of surface color for the hot-pressed compacts (Todaro et al. 2017). The chemical changes were evaluated using Fourier transform infrared (FTIR) spectroscopy (Shangguan et al. 2016). The relationship between the forming temperature, forming pressure, and holding time during hot-pressing and their characteristics were considered.

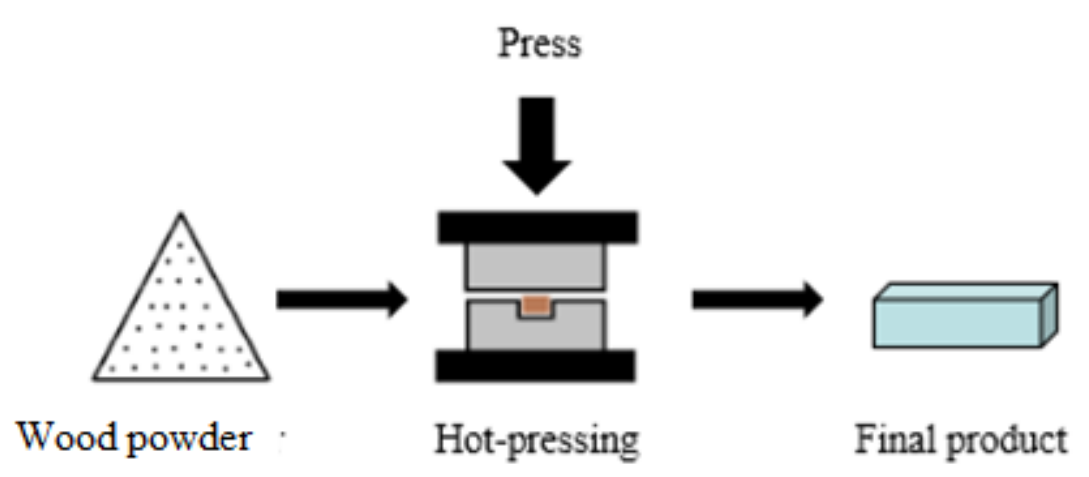

Fig. 1. Flow chart of Hot-pressing

\section{EXPERIMENTAL}

\section{Materials}

Specimen preparation

In this experiment, the poplar powder was used as a raw material. Wooden powder derived from the residue of manufactured poplar (Linyi City Shandong Province, China).

\section{Methods}

The residues of manufactured poplar were first made into powders with a particle size of less than $83 \mu \mathrm{m}$. Poplar powder was prepared with F160 small grinder (Zhongxing Weiye Instrument Co., Ltd., Beijing, China). The moisture content of poplar powder was 9.25\% by the dryer (Shanghai Yiheng Scientific Instrument Co., Ltd, Shanghai, China). The 80 g poplar powder was uniformly spread into the mold of an HX-100 compression machine (Institute of Thermal Processing Engineering, Huazhong University of Science and Technology, Wuhan, China). A total of 16 powder compacts with the $128 \mathrm{~mm} \times 35$ $\mathrm{mm} \times 10 \mathrm{~mm}$ were prepared. The forming conditions of each experiment are shown in Table 1. The pressures for specimens 1 to 5 were set at 40,60, 80, 100, and $120 \mathrm{MPa}$, respectively. The holding time for specimens 6 to 10 was $10,30,50,70$, and $90 \mathrm{~min}$, respectively. The forming temperatures for specimens 11 to 15 are set at 100, 120, 140, 160 , and $180{ }^{\circ} \mathrm{C}$, respectively. The control group was sample 16 with a forming temperature of $100{ }^{\circ} \mathrm{C}$, forming pressure of $30 \mathrm{MPa}$, and holding time of $10 \mathrm{~min}$. 


\section{Static bending strength of specimen}

The static bending strength of the specimens was measured using a WDW-100 universal testing machine (Jinan Shijin Group Co., Ltd., Jinan, China). The indenter coincided with the center line of the specimen length. The bearing span was $80 \mathrm{~mm}$. The loading speed was $0.2 \mathrm{~mm} / \mathrm{s}$.

Table 1. Forming Conditions of Test Specimens

\begin{tabular}{|c|c|c|c|}
\hline Specimen Number & Temperature $\left({ }^{\circ} \mathrm{C}\right)$ & Pressure $(\mathrm{MPa})$ & Holding Time $(\mathrm{min})$ \\
\hline 1 & 140 & 40 & 30 \\
\hline 2 & 140 & 60 & 30 \\
\hline 3 & 140 & 80 & 30 \\
\hline 4 & 140 & 100 & 30 \\
\hline 5 & 140 & 120 & 30 \\
\hline 6 & 140 & 60 & 10 \\
\hline 7 & 140 & 60 & 30 \\
\hline 8 & 140 & 60 & 50 \\
\hline 9 & 140 & 60 & 70 \\
\hline 10 & 140 & 60 & 90 \\
\hline 11 & 100 & 60 & 50 \\
\hline 12 & 120 & 60 & 50 \\
\hline 13 & 140 & 60 & 50 \\
\hline 14 & 160 & 60 & 50 \\
\hline 15 & 180 & 60 & 50 \\
\hline 16 & 100 & 30 & 10 \\
\hline
\end{tabular}

Surface hardness of the specimens

The surface hardness of the specimens was measured using a HV-5 Vickers hardness tester (Dechuan Medical Instrument Co., Ltd., Laizhou, China). The diamond cone with a load of less than $120 \mathrm{~kg}$ and a top angle of $136^{\circ}$ was pressed into the material surface. Then, the diagonal length of the indentation was measured. The surface hardness of the specimen was calculated using Eq. 1. The diamond cone with an apex angle of $136^{\circ}$ was pressed into the material surface at a load of less than $120 \mathrm{~kg}$. Then, the diagonal length of the indentation is measured to calculate the surface hardness of specimen using the following Eq. 1,

$$
H V=0.102 \times \frac{F}{S}=0.102 \times \frac{2 F \sin \frac{a}{2}}{d^{2}}
$$

where $F$ is the load, $a$ is the subtense angle $\left(136^{\circ}\right), S$ is the area of the indentation, and $d$ is the average value of diagonal length.

\section{Measurement of color changes}

The CIELAB method was used to measure the color change with a printer in a constant shading environment. The CIELAB parameters $L^{*}, a^{*}$, and $b^{*}$ were measured (Sun et al. 2017). The $L^{*}$ represents lightness ( $L=0$ for total black, $L=100$ for pure white); $a^{*}$ represents the red-green index ( $+a$ for redness, $-a$ for green); and $b^{*}$ is the yellow-blue index ( $+b$ for yellow, $-b$ for blue). The specimens were scanned using a printer (MP 7502; Ricoh, Tokyo, Japan). Then, the values for $L^{*}, a^{*}$, and $b^{*}$ of the specimens were obtained by the software Photoshop (Adobe Systems, Photoshop CC 2015; San Jose, CA, USA). The total color change $\Delta E^{*}$ was calculated using Eq. 2, 


$$
\Delta E^{*}=\sqrt{\left(\Delta L^{*}\right)^{2}+\left(\Delta a^{*}\right)^{2}+\left(\Delta b^{*}\right)^{2}}
$$

where $\Delta L^{*}, \Delta a^{*}$, and $\Delta b^{*}$ are the color differences between the control group and the treated groups. The average value was calculated according to the values measured at five different positions randomly selected on the blank surface.

\section{FTIR characterization of specimens}

The FTIR spectra of specimens were measured using a Thermo Scientific ${ }^{\text {TM }}$ Nicolet $^{\mathrm{TM}}$ iS10 FTIR Spectrometer (Thermo Fisher Scientific, Waltham, MA, USA). Spectra were measured directly from the surface of specimens via attenuated total reflectance (ATR) technique at a spectral resolution of $4 \mathrm{~cm}^{-1}$ with 32 scans within the scanning range of $400 \mathrm{~cm}^{-1}$ to $4000 \mathrm{~cm}^{-1}$.

\section{RESULTS AND DISCUSSION}

\section{Mechanical Properties of Poplar Powder Compacts}

Effect of the forming pressure on the mechanical properties of the compacts

As the pressing pressure increases, the greater the internal stress introduced, the longer the forming time is required, and the performance of the test piece is improved. Moreover, in the forming process, the holding time is appropriately extended, and the release amount of delayed elastic deformation in the test piece becomes larger, which is beneficial to improve the service life (Chen et al. 2012).

The effect of forming pressure on the mechanical properties of poplar powder compacts is shown in Fig. 2. MOR is the static bending strength of poplar powder compacts. HV is the surface hardness of poplar powder compacts. Figure 1 shows that with the increase in forming pressure, the static bending strength increased slightly first and then decreased.

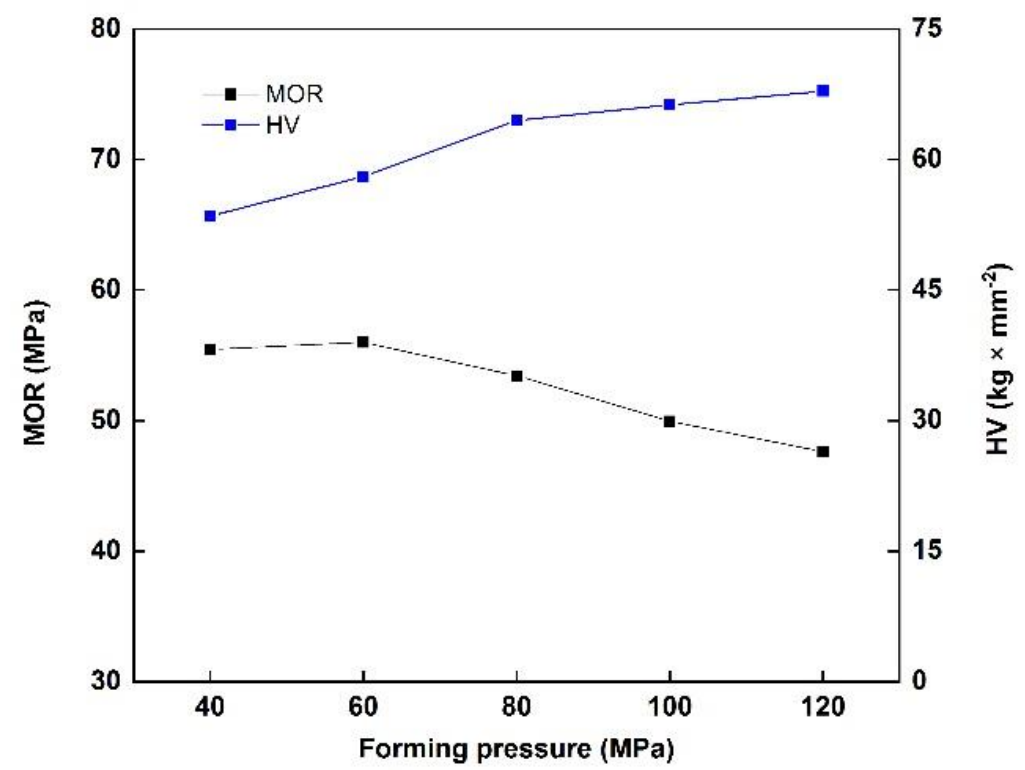

Fig. 2. The effect of the forming pressure on the mechanical properties of the compacts

At present, the static bending strength of commercial fiberboard and particleboard under the same thickness is generally $27 \mathrm{MPa}$ to meet the requirements. The static bending 
strength of hot-pressed poplar wood compact is greater than $45 \mathrm{MPa}$. Therefore, the strength of the poplar wood powder compact prepared by hot-pressing met the requirements. The bending strength reached a maximum value at the forming pressure of $60 \mathrm{MPa}$. This may be due to the degradation of cellulose during hot-pressing, resulting in the decrease of the static bending strength (Yang et al. 2015). The surface hardness of the compacts increased continuously with the increase of forming pressure. The surface hardness of the compacts at $120 \mathrm{MPa}$ was $27 \%$ higher than that at $40 \mathrm{MPa}$. The possible reason is that the lignin content increased with the increase of the forming pressure. The results show that the forming pressure with the best mechanical properties of poplar powder compacts was $60 \mathrm{MPa}$.

\section{Effect of the holding time on the mechanical properties of the compacts}

The effect of holding time on the mechanical properties of poplar powder compacts is shown in Fig. 3. It is shown that with the increase in holding time, the static bending strength of the compacts first increased and then decreased. The bending strength reached a maximum value at the holding time of $50 \mathrm{~min}$. This may be due to the degradation of hemicellulose in the long holding time, resulting in the embrittlement of compacts. Compared with the compacts at the holding time of $10 \mathrm{~min}$, the static bending strength at 50 min increased $13 \%$. The surface hardness of the compacts increased continuously with the increase in holding time. Compared with the compacts at the holding time of $10 \mathrm{~min}$, the surface hardness of the compacts at $90 \mathrm{~min}$ increased $26 \%$. It can be concluded that the mechanical properties were relatively good at the holding time of $50 \mathrm{~min}$.

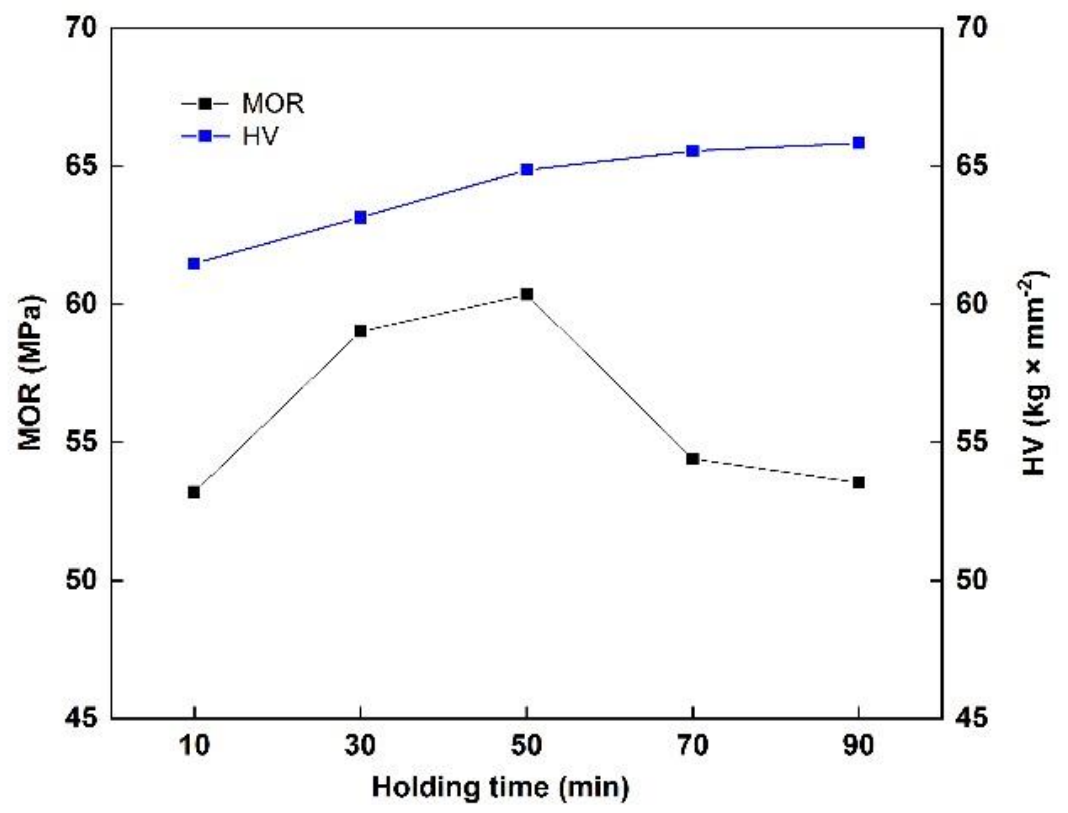

Fig. 3. The effect of holding time on the mechanical properties of the compacts

Effect of the forming temperature on the mechanical properties of the compacts

The effect of the forming temperature on the mechanical properties of poplar powder compacts is shown in Fig. 4. As shown, with the increase in temperature, the static bending strength and surface hardness of the compacts first increased and then decreased. During warm compaction, hemicellulose, cellulose, lignin and other components begin to degrade and recondense to form new materials due to the treatment temperature, so the 
selection of appropriate temperature is particularly important. The results show that when the hot-pressing temperature is $140{ }^{\circ} \mathrm{C}$, the mechanical properties of the compact are the most balanced (Long et al. 2021). The bending strength reached a maximum value at 140 ${ }^{\circ} \mathrm{C}$. The static bending strength at $140{ }^{\circ} \mathrm{C}$ was $34 \%$ higher than that at $100{ }^{\circ} \mathrm{C}$. The increase in temperature can improve the molecular activity of compacts to be conducive to the connection between fibers. However, a temperature that is too high can easily lead to the carbonization of the fiber and decrease the strength of the compact (Sandoval-Torres et al. 2009). The surface hardness reached a maximum value at $160^{\circ} \mathrm{C}$. This may be due to the relative increase in the lignin content during hot-pressing to improve the surface hardness (Wang et al. 2020). It can be concluded that the mechanical properties were relatively good at approximately 140 to $160^{\circ} \mathrm{C}$.

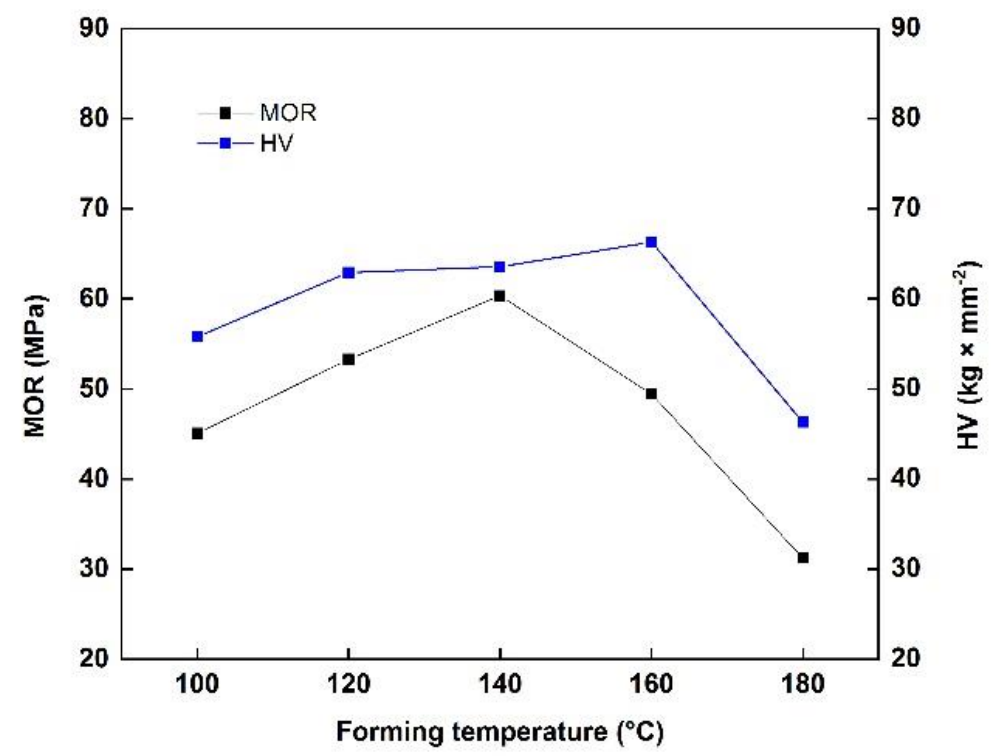

Fig. 4. The effect of the forming temperature on the mechanical properties of the compacts

\section{Color Changes in Poplar Powder Compacts}

Effect of the forming pressure on color changes of the compacts

The effect of the forming pressure on the color changes of the compacts is shown in Figs. 5 and 6. As shown in Fig. 5, the surface color slightly deepened with the increase of the forming pressure. The color parameters $L^{*}$ and $b^{*}$ of the compacts in Fig. 6 decreased with the increase of the forming pressure, and the value $a^{*}$ first increased and then decreased. The effect of the forming pressure on the value $L^{*}$ was more noticeable than the values $\mathrm{a}^{*}$ and $b^{*}$. The lightness value $L^{*}$ decreased from 43 to 32.6. Compared with the control group, the overall color difference $\Delta E^{*}$ also increased with the increase of the forming pressure. These results indicate that the surface color of the compacts deepened with the increase of the forming pressure. This may be due to the degradation of hemicellulose and lignin with the increase of the forming pressure (Zhang et al. 2018). 


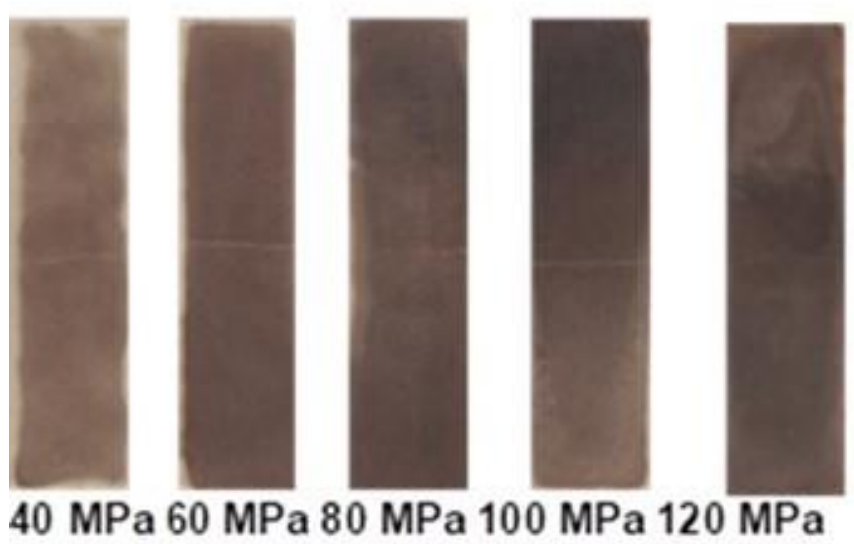

Fig. 5. The effect of the forming pressure on the surface color of the compacts

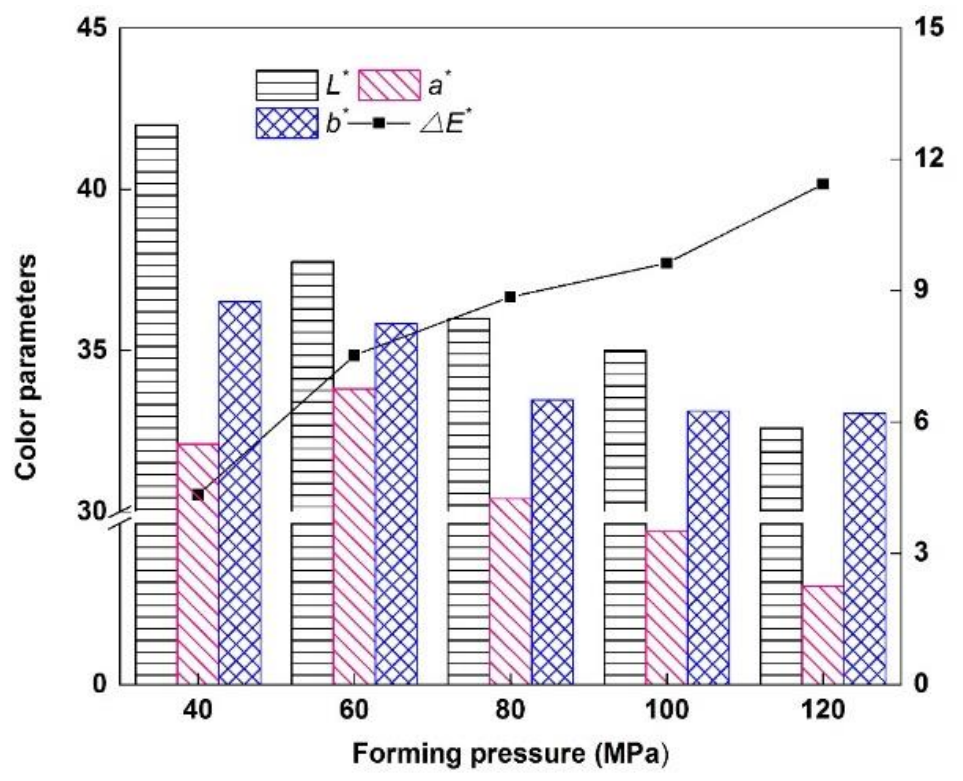

Fig. 6. The effect of the forming pressure on the surface color index of the compacts

Effect of the holding time on color changes of the compacts

Figures 7 and 8 show the effect of the holding time on the color changes of the compacts. As shown in Fig. 7, the surface color of the compacts gradually deepened with the increase of holding time. The color parameters $L^{*}$ and $b^{*}$ of the compacts in Fig. 8 show a decreasing trend with the increase of the holding time. The value $a^{*}$ decreased at the holding time of $70 \mathrm{~min}$ after increasing continuously. The overall color difference $\Delta E^{*}$ increased with the increase of the holding time. This indicates that the surface color of the compacts became darker with the increase of the forming pressure. The changes may also be due to the continuous thermal degradation of chemical components in the compacts with the increase of the holding time (Wang et al. 2016). 

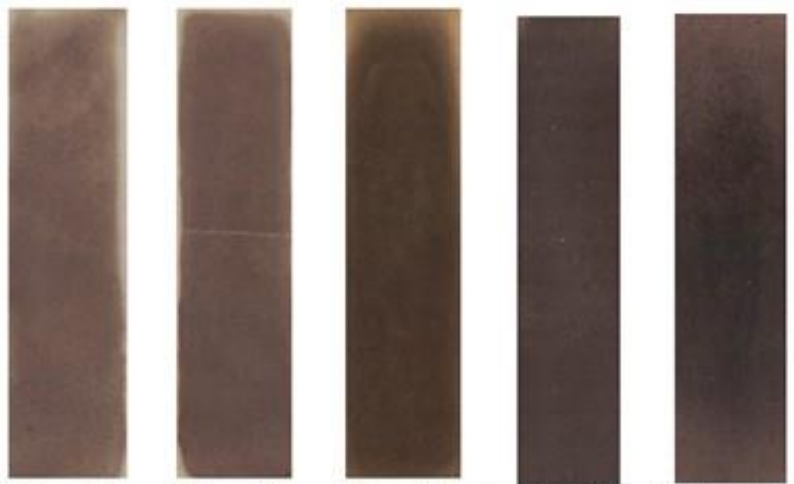

\section{$10 \mathrm{~min} 30 \mathrm{~min} 50 \mathrm{~min} 70 \mathrm{~min} 90 \mathrm{~min}$}

Fig. 7. Effect of the holding time on the surface color of the compacts

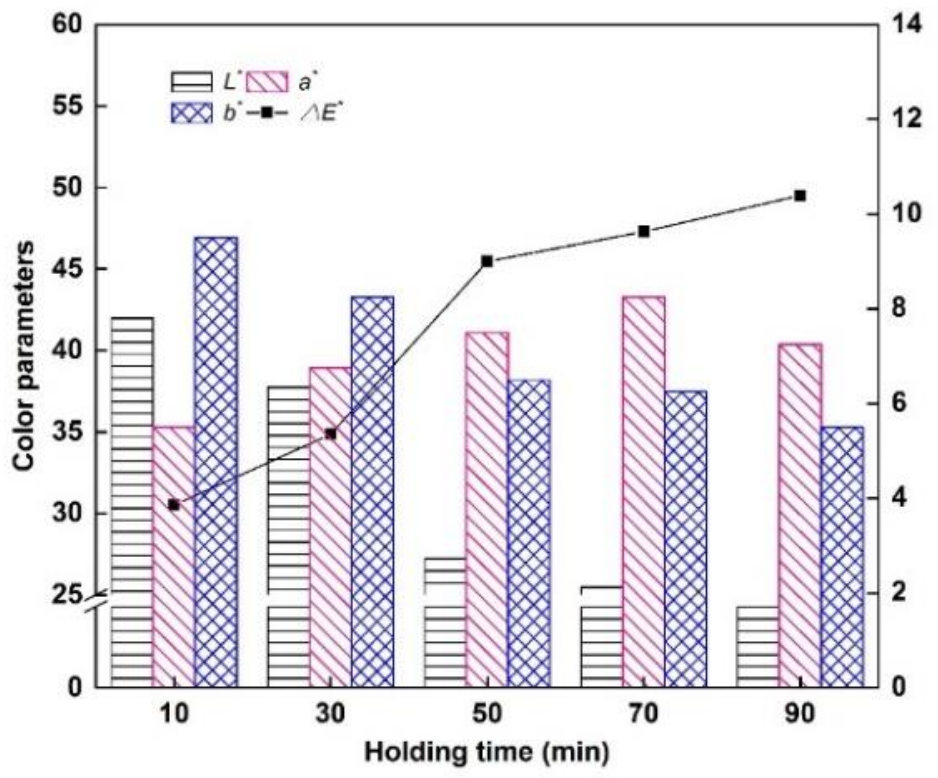

Fig. 8. The effect of the holding time on the surface color index of the compacts

Effect of the forming temperature on color changes of the compacts

Figures 9 and 10 show the effect of the forming temperature on the color changes of the compacts. As shown in Fig. 9, the surface color of the compacts gradually deepened with the increase of the forming temperature. Similarly, the lightness value $L^{*}$ in Fig. 10 shows a continuous decreasing trend and the overall color difference $\Delta E^{*}$ increased with the increase of the forming temperature. The increase of the temperature will promote the degradation and condensation of lignin in the compacts to form ketones or quinones (Matsuo et al. 2016). This results in the deepening of the surface color of the compact with the increase of the forming temperature. 


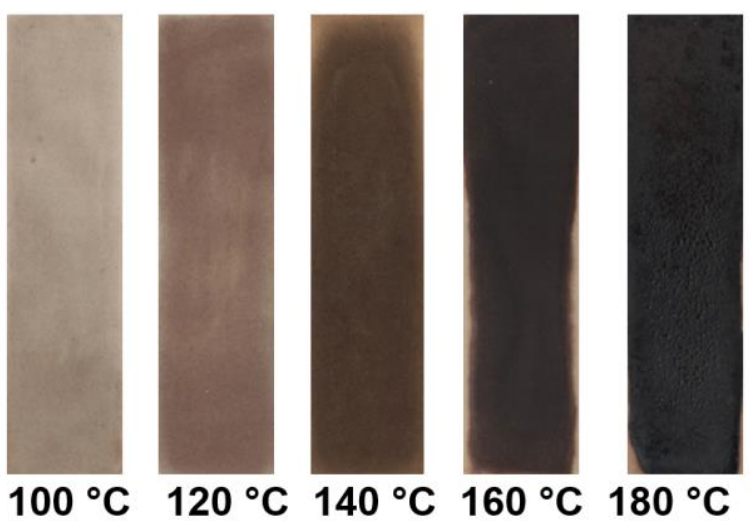

Fig. 9. The effect of the forming temperature on the surface color of the compacts

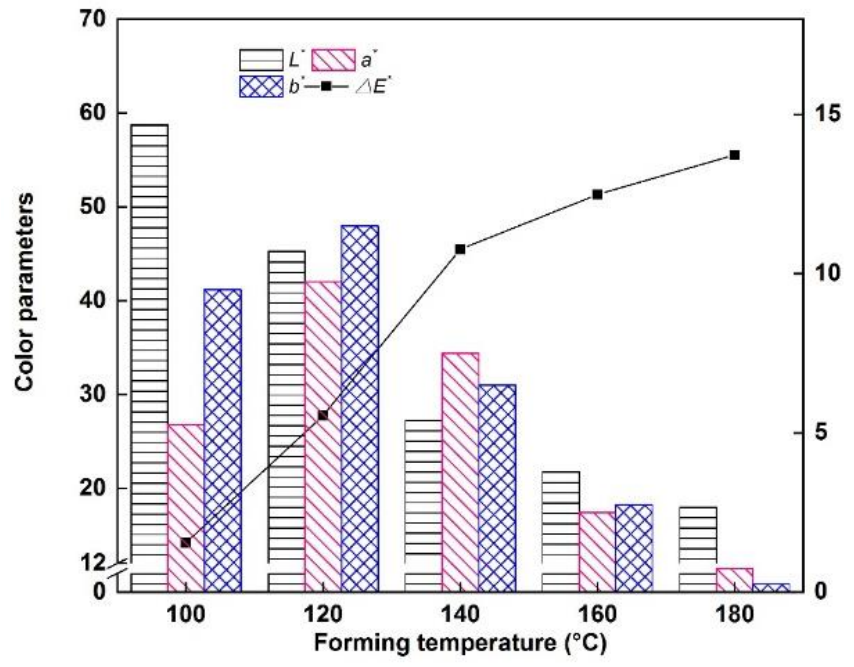

Fig. 10. The effect of the forming temperature on the surface color index of the compacts

\section{Chemical Changes in Poplar Powder Compacts}

Figure 11 shows the infrared spectrum of the compacts at different forming temperatures. As shown in Fig. 11, the absorption peak at $3383 \mathrm{~cm}^{-1}$ represents the stretching vibration of hydroxyl $\mathrm{OH}$.

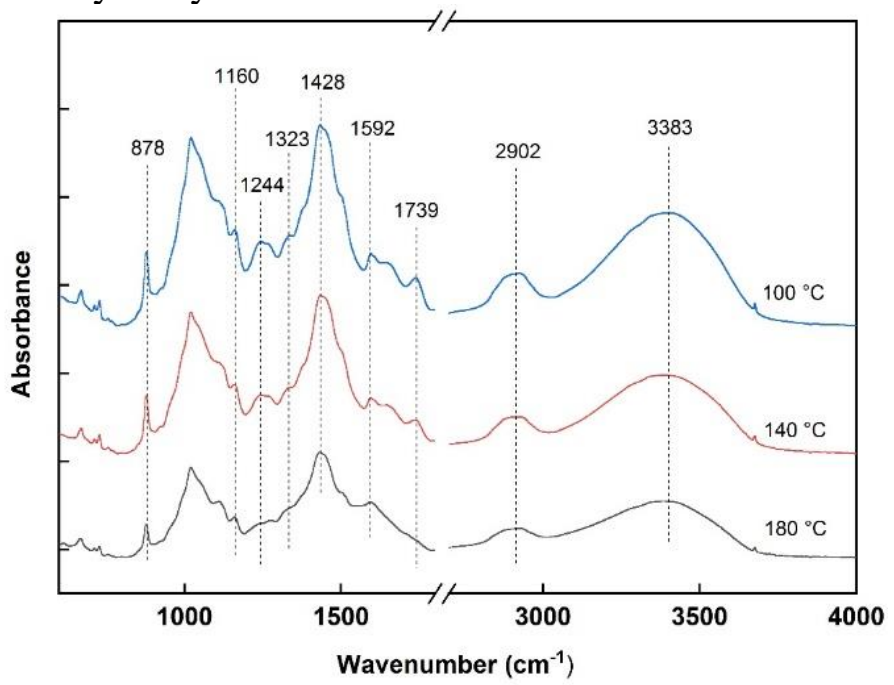

Fig. 11. Infrared spectrum of the formed compacts at different forming temperatures 
With the increase of the forming temperature, the intensity of the absorption peak gradually decreased. The absorption peak at $1739 \mathrm{~cm}^{-1}$ indicates the stretching vibration of carbonyl $\mathrm{C}=\mathrm{O}$ in acetyl group, and the intensity of this absorption peak decreased. This indicates that the deacetylation of hemicellulose occurs, and the release of acetic acid will aggravate the degradation of the acetyl group (Fu et al. 2017). Additionally, it can catalyze the degradation and polycondensation of cellulose and polysaccharides. The absorption peak at $1592 \mathrm{~cm}^{-1}$ indicates the stretching vibration of aromatic $\mathrm{C}=\mathrm{C}$ in lignin. The decrease of the intensity of the absorption peak may be due to the degradation of lignin. The absorption peak at $1244 \mathrm{~cm}^{-1}$ represents the ether $\mathrm{C}-\mathrm{O}-\mathrm{C}$ of lignin, and the peak strength decreased with the increase of the forming temperature. With the increase of forming temperature, the lignin content of poplar powder blank increased gradually (Srinivas and Pandey 2012). This indicates that the decomposition of lignin branched chain in the hotpressing process promoted the condensation reaction of lignin and produced colored substances, which led to the deepening of the surface color. This is consistent with the change of the color of poplar powder blank with the forming process

Figure 12 shows the infrared spectrum of the compacts at different forming pressures. As shown in Fig.12, the absorption peak at $2902 \mathrm{~cm}^{-1}$ represents the stretching vibration of the $\mathrm{C}-\mathrm{H}$ of cellulose (Albrektas and Navickas 2017). The intensity of the absorption peak decreased with the increase of the forming pressure. This indicates that the increase of the forming pressure caused the degradation of cellulose and other substances. The absorption peaks at $1430 \mathrm{~cm}^{-1}$ and $878 \mathrm{~cm}^{-1}$ indicate that the $\mathrm{CH}_{2}$ shear vibration and $\mathrm{C}-\mathrm{H}$ deformation vibration of cellulose (Wang et al. 2020). After hot-pressing, the intensity of this absorption peak decreased. It was apparent that cellulose has different degrees of degradation, leading to the reduction of cellulose content. Therefore, the surface color of the poplar powder compacts gradually deepened with the increase of the forming pressure.

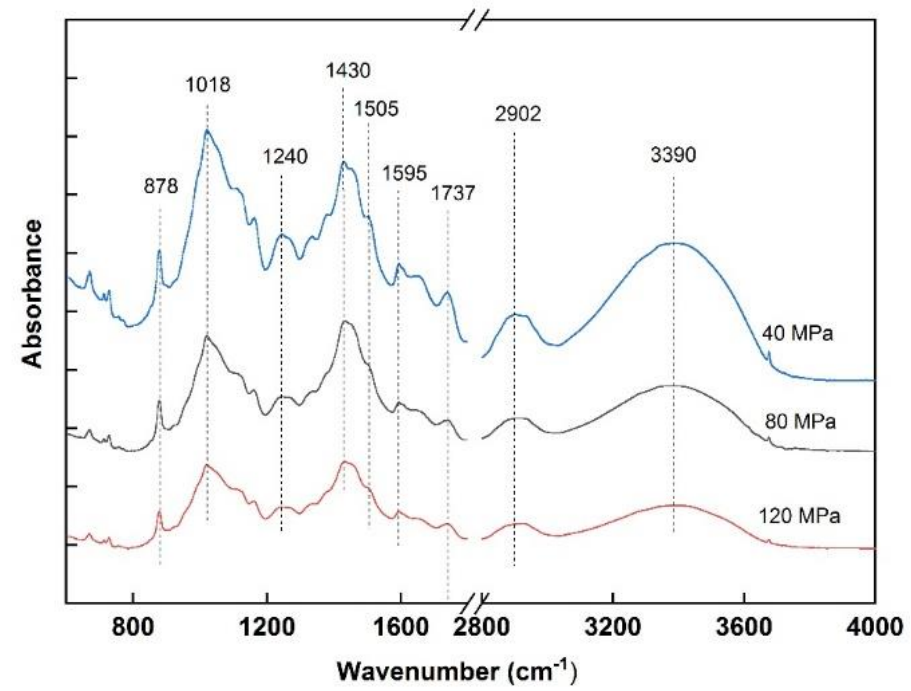

Fig. 12. Infrared spectrum of the formed compacts at different forming pressures

Figure 13 shows the infrared spectra of the compacts at different holding times. The decrease of absorption peak intensity at $1739 \mathrm{~cm}^{-1}$ was due to the deacetylation and pyrolysis of hemicellulose (Zheng et al. 2016). The absorption peaks at $1595 \mathrm{~cm}^{-1}$ and 1507 $\mathrm{cm}^{-1}$ indicate the skeleton vibration of lignin, and the intensity of the absorption peak did not change noticeably. This shows that the effect of the holding time on lignin was 
relatively small at $140{ }^{\circ} \mathrm{C}$. The absorption peak at $878 \mathrm{~cm}^{-1}$ indicates the $\mathrm{C}-\mathrm{H}$ vibration of the cellulose structure in the compacts. Lignin contains a variety of functional groups causing the change of color. The functional groups in lignin begin to play a role as the temperature increases and lead to gradually deepening color of the poplar power compact. The decrease of the absorption peak intensity may be due to the degradation of cellulose in the non-crystalline region. The degradation of cellulose led to the darkening of the surface color of the poplar powder compacts.

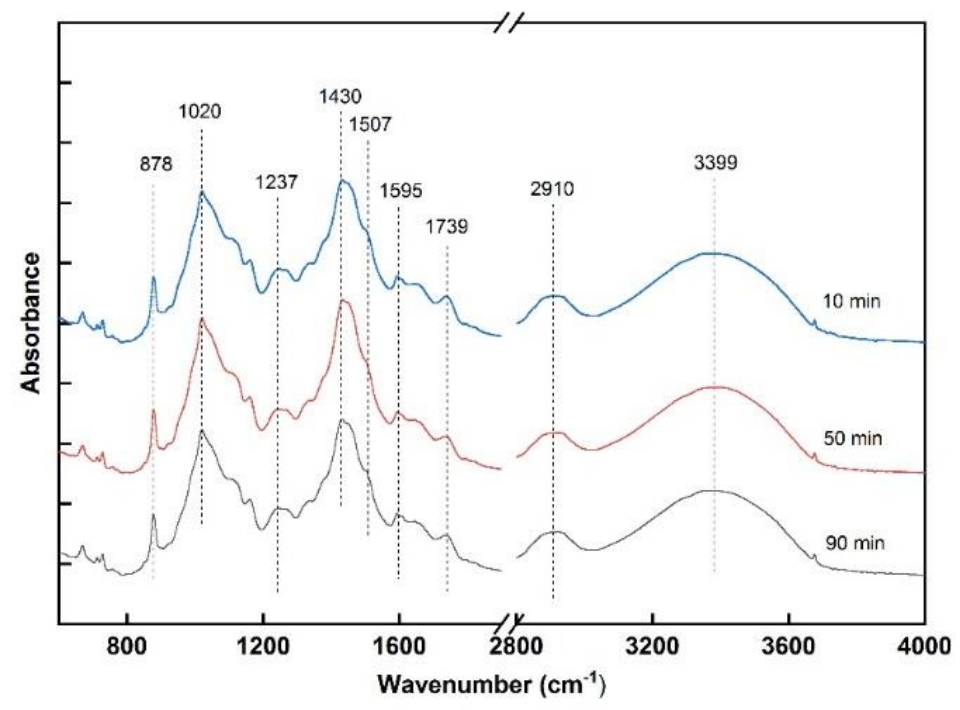

Fig. 13. Infrared spectrum of the formed compacts at different holding times

\section{CONCLUSIONS}

1. The static bending strength first increased and then decreased with the increase of forming pressure, holding time, and forming temperature. The static bending strength reached a maximum value at a forming pressure of $60 \mathrm{MPa}$, holding time of $50 \mathrm{~min}$, and forming temperature of $140{ }^{\circ} \mathrm{C}$. The surface hardness increased with the increase in forming pressure and holding time. With the increase in forming temperature, it increased first and then decreased to a minimum value at $180^{\circ} \mathrm{C}$.

2. The surface color of the compacts gradually deepened with the increase in forming pressure, holding time and forming temperature. The lightness value $L^{*}$ decreased gradually. The value $a^{*}$ increased slightly at first and then decreased. The value $b^{*}$ decreased gradually with the increase in forming pressure and holding time. The value $b^{*}$ increased first and then decreased with the increase in forming temperature.

3. The Fourier transform infrared (FTIR) analysis revealed that the degradation of cellulose and hemicellulose to generate a new structure led to the surface color of compacts deepening. In the hot-pressing process, hemicellulose began to degrade first, and the skeleton structure of lignin was relatively more stable than the side chain. These components produced a lot of chromogenic groups and auxiliary groups, during the process of degradation or polycondensation. During hot-pressing, the contents of polysaccharides, lignin, and extractives increased. The decrease of relative intensity of absorption peak at $1739 \mathrm{~cm}^{-1}$ indicates the degradation of hemicellulose, and the 
decrease of relative intensity of absorption peak at $2910 \mathrm{~cm}^{-1}$ indicates the degradation of $\mathrm{C}-\mathrm{H}$ bond of cellulose. In the infrared spectra of compacts under different forming pressures, the decrease in the relative intensity of the absorption peaks at $1595 \mathrm{~cm}^{-1}$ and $1240 \mathrm{~cm}^{-1}$ indicates a decrease in the relative content of the skeleton $\mathrm{C}-\mathrm{C}$ bond and the side chain $\mathrm{C}-\mathrm{O}$ bond in the lignin structure. In the infrared spectra of compacts under different holding times, the absorption peaks at $1595 \mathrm{~cm}^{-1}$ and $1507 \mathrm{~cm}^{-1}$ have little change in intensity, indicating that the holding time has relatively little effect on the degradation of lignin. The results showed that the polysaccharides in the compacts were degraded after hot-pressing, and the content of lignin and extracts increased, indicating that the content of colored substances in the compacts increased after hot-pressing, which made the wood color darker.

\section{ACKNOWLEDGEMENTS}

This work was supported by funding from the Scientific Research Project of Hunan Provincial Department of Education (No. 19A512), the Changde Joint Funds of Natural Science Foundation of Hunan Province (No. 2020JJ6065), the Key Research and Development Project of Hunan Province (No. 2019GK2244), the Natural Science Foundation of Hunan Province (No. 2018JJ2681), and the Scientific Innovation Fund for Post-graduates of Hunan Provincial (No. CX20190628).

\section{REFERENCES CITED}

Albrektas, D., and Navickas, P. (2017). "An evaluation of modulus of elasticity, dimensional stability and bonding strength of bonded heat-treated wood," Drvna Industrija 68(2), 137-144. DOI: 10.5552/drind.2017.1641

Chen, Y., Fan, Y. M., and Gao, J. M. (2012). "The effect of heat treatment on the chemical and color change of black locust (Robinia pseudoaca-cia) wood flour," BioResources 7(1), 1157-1170. DOI: 10.15376/biores.7.1.1157-1170

Fu, Z., Avramidis, S., Zhao, J., and Cai, Y. (2017). “Artificial neural network modeling for predicting elastic strain of white birch disks during drying," European Journal of Wood and Wood Products 75(6), 949-955. DOI: 10.1007/s00107-017-1183-X

Long, Z. Z., Zhang, L. Q., Wu, Q. D., Tan, Z. L., and Guo, P. C. (2021). "Effect of temperature on color and chemical of poplar powder compacts during warm-press forming," European Journal of Wood and Wood Products 27, 1-8. DOI: 10.1007/s00107-021-01696-0

Matsuo, M. U., Mitsui, K., Kobayashi, I., Kohara, M., Yoshida, M., and Yamamoto, H. (2016). "Effect of hygrothermal treatment on wood properties: Color changes and kinetic analysis using four softwood and seven hard species," Wood Science and Technology 50(6), 1145-1160. DOI: 10.1007/s00226-016-0833-1

Shangguan, W., Gong, Y., Zhao, R., and Ren, H. (2016). "Effects of heat treatment on the properties of bamboo scrimber," Journal of Wood Science 62, 383-391. DOI: 10.1007/s10086-016-1574-3

Srinivas, K., and Pandey, K. (2012). "Effect of heat treatment on color changes, dimensional stability, and mechanical properties of wood," Journal of Wood Chemistry and Technology 32(4), 304-316. DOI: 10.1080/02773813.2012.674170 
Sun, B., Wang, Z., and Liu, J. (2017). "Changes of chemical properties and the water vapour sorption of Eucalyptus pellita wood thermally modified in vacuum," Journal of Wood Science 63, 133-139. DOI: 10.1007/s10086-016-1601-4

Todaro, L., Rita, A., Mecca, M., and Hiziroglu, S. (2017). "Influence of thermos-vacuum treatment on thermal degradation of various wood species," European Journal of Wood and Wood Products 76, 541-547. DOI: 10.1007/s00107-017-1230-7

Wang, X., Hou, Q., Zhang, X., Zhang, Y., Liu, W., Xu, C., and Zhang, F. (2020). "Color evolution of poplar wood chips and its response to lignin and extractives changes in autohydrolysis pretreatment," International Journal of Biological Macromolecules 157, 673-679. DOI: 10.1016/j.ijbiomac.2019.11.224

Wang, Z., Sun, B., and Liu, J. (2016). "Effect of thermo-vacuum treatment on the color and chemistry of larch wood," BioResources 11(1), 2349-2360. DOI: 10.15376/biores.11.1.2349-2360

Yang, Y., Zhan, T. Y., Lu, J. X., and Jiang, J. H. (2015). "Influences of thermo-vacuum treatment on colors and chemical compositions of alder birch wood," BioResources 10(4), 7936-7945. DOI: 10.15376/biores.10.4.7936-7945

Zhang, L., Long, Z., Tan, Z., and Wu, Q. (2020). “Temperature's effect on color change and mechanical properties of poplar powder compact formed by warm compaction," BioResources 15(3), 7009-7017. DOI: 10.15736/biores.15.3.7009-7017

Zhang, P., Wei, Y., Liu, Y., Chen, Y., Gao, J., and Fan, Y. (2018). "Heat-induced discoloration of chromophore structures in eucalyptus lignin," Materials 11(9), 16861690. DOI: 10.20944/preprints201807.0286.v1

Zheng, A., Jiang, L., Zhao, Z., Chang, S., Huang, Z., Zhao, K., He, F., and Li, H. (2016). "Effect of hydrothermal treatment on chemical structure and pyrolysis of eucalyptus wood," Energy \& Fuels 30(4), 3057-3065. DOI: 10.1021/acs.energyfuels.5b03005

Article submitted: February 15, 2021; Peer review completed: April 25, 2021; Revised version received: May 9, 2021; Accepted: May 13, 2021; Published: May 24, 2021. DOI: $10.15376 /$ biores.16.3.4934-4946 